\title{
Association between body mass index, diet and dental caries in Grade 6 boys in Medina, Saudi Arabia
}

A. Bhayat ${ }^{1,2}$, M.S. Ahmad' ${ }^{2}$,H.T. Fadel ${ }^{2}$

$$
\begin{aligned}
& \text { العلاقة بين مقياس كتلة الجسم و النظام الغذائي وتسوس الأسنان عند التلاميذ الذكور بالصف السادس في المدينة المنورة بالمملكة } \\
& \text { أحمد بهايات، محمد سامي أحمد، هاني طلال فاضل }
\end{aligned}
$$

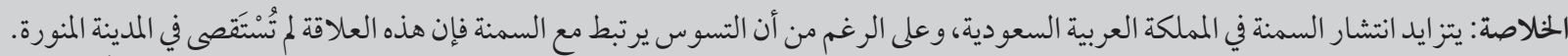

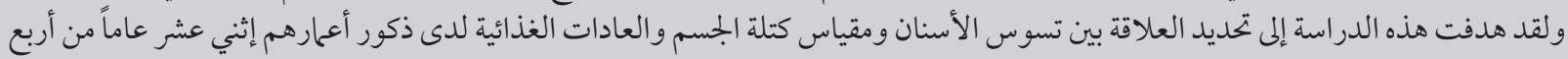

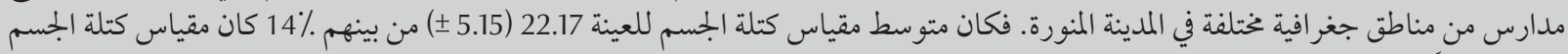

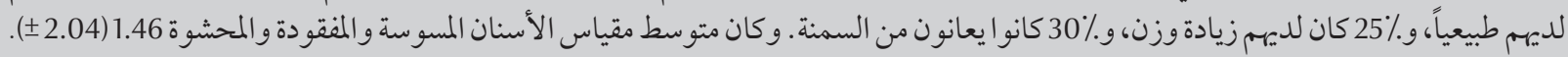

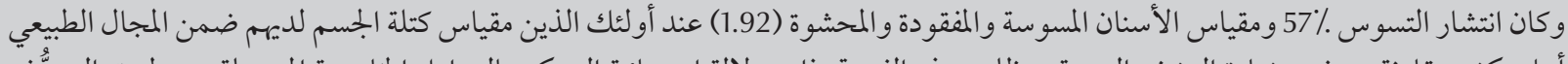

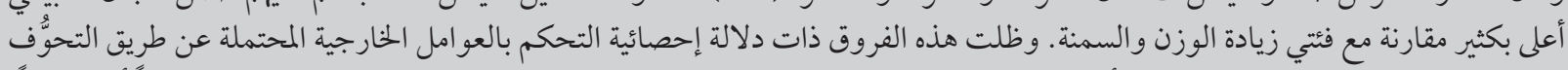

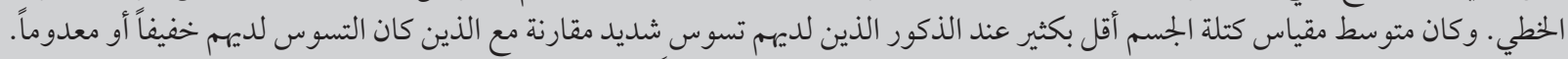

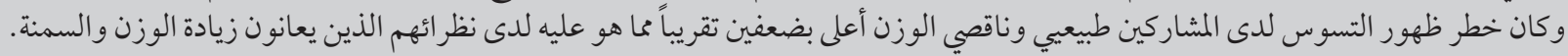

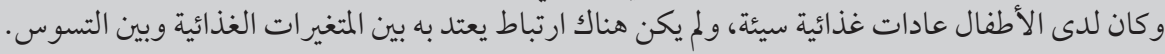

ABSTRACT The prevalence of obesity is increasing in Saudi Arabia and although caries is associated with obesity, this association has not been investigated in Medina. This study aimed to determine the association between dental caries, body mass index (BMI) and dietary habits of 12-year-old boys from four geographically distinct schools in Medina. Mean BMI was $22.17 \mathrm{~kg} / \mathrm{m}^{2}$ ( \pm 5.15); 41\% had normal BMI, 25\% were overweight and 30\% were obese. The mean Decayed, Missing and Filled Teeth (DMFT) score was $1.46( \pm 2.04)$. Those in the normal BMI range had a significantly higher prevalence of caries (57\%) and DMFT score (1.92) compared with the overweight and obese groups $(P<0.05)$. These differences remained significant after controlling for possible confounders via linear regression. Mean BMI was significantly lower in boys with severe compared with mild or no caries. Normal and underweight participants had an almost 2 times greater risk of developing caries compared with their overweight and obese counterparts. The children had poor dietary habits and there were no significant associations between dietary variables and caries.

Association entre l'indice de masse corporelle, le régime alimentaire et les caries dentaires chez des garçons en dernière année de primaire à Médine (Arabie saoudite)

RÉSUMÉ La prévalence de l'obésité augmente en Arabie saoudite et malgré le lien qui existe entre la carie et l'obésité, cette association n'a pas été étudiée à Médine. La présente étude avait pour objectif de déterminer I'association entre les caries dentaires, I'indice de masse corporelle (IMC) et les habitudes alimentaires de garçons âgés de 12 ans venant de quatre écoles géographiquement distinctes à Médine. L'IMC moyen était de $22,17 \mathrm{~kg} / \mathrm{m}^{2}( \pm 5,15) ; 41 \%$ avaient un IMC normal, $25 \%$ étaient en surcharge pondérale et $30 \%$ étaient obèses. Le score moyen de l'indice CAO (dent cariée, absente ou obturée) s'élevait à 1,46 ( $\pm 2,04)$. Les garçons dont l'IMC se situait dans les valeurs normales avaient un prévalence de la carie $(57 \%)$ et un indice CAO supérieurs $(1,92)$ à ceux du groupe des enfants en surcharge pondérale et souffrant d'obésité $(p<0,05)$. Ces différences demeuraient significatives après avoir contrôlé d'autres facteurs de confusion potentiels grâce à la régression linéaire. L'IMC moyen était considérablement plus faible chez les garçons ayant des caries sévères par rapport à ceux qui avaient des caries bénignes ou qui n'en avaient pas. Les participants de poids normal ou présentant une insuffisance pondérale avaient un risque deux fois plus important de développer des caries que ceux qui étaient en surcharge pondérale ou obèses. Les enfants avaient de mauvaises habitudes alimentaires et il n'y avait aucune association entre les variables alimentaires et les caries. 


\section{Introduction}

There is a strong association between nutritional status and dental caries, and a direct link between caries, sugar consumption and obesity $(1,2)$. Some studies have reported a positive correlation between caries and obesity, whereas others have shown that underweight children tend to have a higher prevalence of caries compared to their overweight counterparts $(1,2)$.

Dental caries is a worldwide epidemic affecting children of all ages $(3,4)$. Its aetiology is multifactorial and includes plaque accumulation, poor oral hygiene and consumption of fermentable carbohydrates (2). Obesity is also multifactorial and its risk factors include poor eating habits, lack of physical activity, genetics and increased consumption of carbohydrates (3).

Children with caries may present with pain and ultimately tooth loss. This could result in a reduction in food intake, which in turn may lead to stunting of growth (3). In contrast, increased consumption of fermentable carbohydrates can result in increased body weight and prevalence of dental caries (4).

Body mass index (BMI) is currently used as the gold standard to determine anthropometric score and classifies individuals into four groups; underweight, normal weight, overweight and obese (3). Although there have been conflicting results regarding the association between caries and BMI, this association has not been studied in grade 6 children in Medina. Saudi Arabia has one of the highest obesity levels in the world, which could be due to its rapid growth and economic development over the past few years and the widespread introduction and consumption of fast foods and soft drinks $(5,6)$.

This study was carried out in the city of Medina, which is located in North West Saudi Arabia. It is the second holiest site in the Islamic world after Mecca.
The aim of the study was to determine the relationship between dental caries, BMI and dietary intake of 12-year-old schoolchildren in Medina.

\section{Methods}

\section{Study design}

This was a cross-sectional analytical study of Grade 6 schoolboys carried out between February and April 2014. The sample size was calculated by estimating the population of 12 year-old boys in Medina to be 10000 (7). Assuming the prevalence of obesity to be $23 \%$ (8) with a confidence level of $95 \%$ and marginal error of $\sim 0.05$, a minimum sample size of 370 participants was required. There were 194 male primary schools in Medina and these were divided into 4 geographical areas as follows: North, 40 schools; South, 51 schools; West, 52 schools and East, 51 schools. One school was selected from each cluster using a convenience sampling strategy. All grade 6 students from each of the four schools were invited to participate in the study. A total of 419 participants received consent forms for their parents to sign; this ensured that the minimum sample size would be achieved.

\section{Data collection}

The data collection consisted of 3 parts: a clinical oral examination; completion of a dietary questionnaire; and measuring body height and weight.

The oral examinations were performed in classrooms under fluorescent lighting with the participant sitting on a school chair according to the World Health Organization (WHO) criteria (9). The Decayed, Missing and Filled Teeth (DMFT) index was used to record the caries status of the permanent dentition. The primary dentition was excluded. Only teeth with frank caries were diagnosed as decayed while those with early white spot lesions, unconfirmed caries or fissure sealants were recorded as sound. Teeth that were extracted because of caries were recorded as missing, while teeth removed due to trauma or orthodontic treatment were recorded as healthy according to the WHO criteria (9). Two dentists who had been trained in the diagnosis of dental caries using the DMFT index index completed the oral examinations. Calibration was done using slides and mounted extracted teeth and $\mathrm{\kappa}$ scores of 0.90 and 0.80 were obtained for intraand inter-examiner reliability, respectively. For simplicity, the DMFT score was divided into 3 categories at the time of data presentation: 0 , no caries; $1-3$, mild caries; and $\geq 4$, severe caries.

A standardized dietary questionnaire $(10,11)$ was used to determine the nutritional intake and physical activity of the participants. A pilot study, to validate the questionnaire, was carried out on 45 boys at the first school. Minor changes were made to the questionnaire and the modified version was used at the remaining schools. Data from the first school was included in the final analysis because there was sufficient overlap between the initial and latter information that was collected. The questionnaire was self-administered and consisted of 12 closed and 1 openended questions. The questions were related to the consumption of junk foods such as burgers, pizzas and sweets, soft drinks, milk, water, fruit and vegetables, and the frequency of physical activities.

Trained dental students, using a medical scale to the nearest $100 \mathrm{~g}$ and a standardized height measuring tape in meters to the nearest centimetre, recorded the weight and height respectively. The participants removed their shoes and heavy garments before their height and weight were recorded. The BMI was calculated by dividing the weight in kilograms by the square of the height in metres $\left(\mathrm{kg} / \mathrm{m}^{2}\right)(12)$. The recorded height and weight were classified according to the WHO BMI categories using age-related guidelines into underweight, normal, overweight or obese (12). 


\section{Oral hygiene}

The participants received a 15 -minute presentation regarding oral hygiene practices and healthy eating habits. They were shown how to brush and floss their teeth and all participants received a toothbrush, toothpaste and pamphlets containing information on brushing and oral hygiene practices. A referral form was issued to those who were in need of dental treatment and they were advised to visit the Taibah University Dental College \& Hospital for further assessment and management.

\section{Statistical analyses}

Descriptive statistics including the percentages, means and standard deviations (SDs) were obtained. The $\chi^{2}$ test was used to test the significance of the categorical data in the different BMI and DMFT groups. Analysis of variance (ANOVA) and Kruskal-Wallis tests were used when comparing the continuous data, mean DMFT and mean BMI scores. Linear regression analysis was used to assess whether significance levels remained after controlling for possible confounding variables. BMI was considered the dependent variable and DMFT score was considered the independent variable. Age, school, freque ncy of snacks between meals, consumption of soft drinks, milk, fruit and vegetables, and daily sports activities were all considered as possible confounders and were eventually entered into the model simultaneously to achieve the best model fit. Confounders were entered initially in a stepwise manner to observe the change in the $R^{2}$ value, which increased from $3 \%$ to $11 \%$ at most, possibly inferring a poor model fit. However, the standard error of the regression was lowered from 6 to 5 , inferring a prediction interval of up to $90 \%$. A probability plot was used for regression model diagnostics to detect any possible nonlinearity or non-normality of the model. The results of the model diagnostics turned out negative. Logistic regression was also done using caries as the binary dependent variable and BMI, age, school, sport activities and dietary intake as independent variables. The crude and adjusted odds ratios (ORs) were calculated to assess the odds of developing caries in the different BMI groups. In all instances, the significance level was set at $P<0.05$. Data were analysed using SPSS Statistics for Windows, version 17.0, released in 2008 (Chicago, IL, USA).

\section{Ethical clearance}

Ethical clearance was obtained from the Taibah Dental Ethics Committee (TUCDREC/20130512/Bhayat) and all information was strictly confidential and anonymous.

\section{Results}

The parents of 402 of the 419 participants provided signed consent, yielding a response rate of $96 \%$. Those who were not included either did not have signed consent forms or were absent on the day of the clinical examination. The mean age of the participants was 12.6 years $( \pm 0.62$; range $12-14$ years) and mean DMFT score was $1.46( \pm 2.04$; range 0-9) (Table 1). The median DMFT score was 0.0 and the decayed, missing and filled components contributed 86, 3 and $11 \%$ of the total DMFT score, respectively.

The mean BMI was $22.17( \pm 5.15)$ $\mathrm{kg} / \mathrm{m}^{2}$. Sixteen (4\%) of the schoolboys were underweight, 165 (41\%) were within the normal range, 100 (25\%) were overweight and 121 (30\%) were obese (Table 1). Boys in the normal and underweight groups had a significantly higher prevalence of caries $(P<0.05)$ and DMFT score $(P<0.01)$ compared to the overweight and obese groups (Table 1). Because there were only 16 (4\%) boys classified as underweight, they were combined with the normal category for ease of analysis and referred to as the normal weight group. The differences among the 3 BMI groups in terms of DMFT score remained significant after controlling for possible confounders by means of linear regression analysis $(P<0.01)$ (Table 2$)$. When calculating the unadjusted $\mathrm{OR}$, normal weight children were 1.3 times more likely to develop caries compared to overweight and obese children $(P<$ 0.05) (Table 3). Furthermore, when adjusting for age, school, sport activities

\begin{tabular}{|c|c|c|c|c|c|c|}
\hline & \multirow{2}{*}{$\begin{array}{c}\text { Total } \\
(n=402)\end{array}$} & \multicolumn{5}{|c|}{ BMI groups } \\
\hline & & $\begin{array}{l}\text { Underweight } \\
(n=16 ; 4 \%)\end{array}$ & $\begin{array}{c}\text { Normal } \\
(n=165 ; 41 \%)\end{array}$ & $\begin{array}{c}\text { Overweight } \\
(n=100 ; 25 \%)\end{array}$ & $\begin{array}{c}\text { Obese } \\
(n=121 ; 30 \%)\end{array}$ & $P$ value \\
\hline Mean D (SD) & $1.26(1.87)$ & $2.00(2.78)$ & $1.67(2.16)$ & $0.92(1.60)$ & $1.01(1.56)$ & $0.002 *$ \\
\hline Mean M (SD) & $0.04(0.30)$ & $0.25(0.68)$ & $0.06(0.39)$ & $0.05(0.30)$ & $0.01(0.09)$ & $0.022^{*}$ \\
\hline Mean F (SD) & $0.16(0.50)$ & $0.38(0.72)$ & $0.20(0.58)$ & $0.19(0.48)$ & $0.09(0.37)$ & 0.119 \\
\hline Mean DMFT (SD) & $1.46(2.04)$ & $2.63(3.34)$ & $1.92(2.35)$ & $1.16(1.85)$ & $1.11(1.62)$ & $0.001^{*}$ \\
\hline Prevalence of caries (\%) & 49 & 63 & 57 & 42 & 43 & $0.031^{* *}$ \\
\hline
\end{tabular}

*Statistically significant at the 0.01 level using Kruskal-Wallis test.

${ }^{*}$ Statistically significant at the 0.05 level using $\chi^{2}$ test.

$B M I=$ body mass index $;$ DMFT = decayed, missing and filled teeth . 


\begin{tabular}{|c|c|c|c|c|}
\hline Independent variable & $\begin{array}{l}\text { Regression } \\
\text { coefficient } \\
\quad(R)\end{array}$ & $\begin{array}{r}\text { Coefficient of } \\
\text { determination } \\
\left(R^{2}\right)\end{array}$ & $\begin{array}{c}\text { Standard error of regression } \\
\text { (S) }\end{array}$ & $P$ value \\
\hline DMFT & 0.327 & 0.107 & 5.0 & $P<0.01$ \\
\hline
\end{tabular}

Adjustments for possible confounders were made by entering age; school; frequency of eating snacks between meals; consuming soft drinks, milk, fruit and vegetables; and daily sports activities into the linear regression model, all at once. P values in bold are statistically significant.

${ }^{a}$ Regression analysis was performed on only 319 participants who answered all items/variables that were selected as possible confounders. $B M I=$ body mass index; DMFT = decayed, missing and filled teeth .

and dietary intake variables, the normal weight children were almost 1.8 times more likely to develop caries compared to those who were overweight and obese $(P<0.05)$.

The participants were also divided into 3 groups based on their DMFT score (13). There were significant differences in the mean BMI scores among the 3 caries severity groups $(P<0.01)$ (Table 4). Those who were caries free $(\mathrm{DMFT}=0)$ had the highest mean BMI $\left(22.69 \mathrm{~kg} / \mathrm{m}^{2}\right)$, while those with severe caries $(\mathrm{DMFT} \geq 4)$ had the lowest mean BMI $\left(20.26 \mathrm{~kg} / \mathrm{m}^{2}\right)$.

Regarding the dietary intake, less than half of the participants reported eating fruit and vegetables daily (Figure 1). The majority (97\%) reported drinking up to 4 glasses of soft drinks per day, while $72 \%$ reported drinking $<5$ glasses of water daily. At school, almost 20\% reported eating junk foods, of which, the most common were hamburgers (38\%), desserts (8\%), chocolates (6\%) and chips (5\%). Only 3\% ate fruit at school and 2\% reported drinking milk daily. There were no significant associations between any of the age, school and dietary habits and the DMFT score and these were therefore excluded from the analysis.

\section{Discussion}

The aim of this study was to determine the association between dental caries, BMI and dietary habits of Grade 6 schoolboys in Medina. The mean DMFT score was 1.46, which was within the target set by the WHO and the range (1.31-1.53) reported by previous studies in Medina $(13,14)$. Although the mean DMFT score was low, $49 \%$ of the sample were diagnosed with caries, of which, $15 \%$ had severe caries. In addition, $86 \%$ of the decayed teeth were untreated. This shows the skewed distribution of caries and may be a result of poor utilization of dental services due to fear, geographic location, high costs, lack of oral hygiene practices and poor oral hygiene education $(15,16)$. The heterogeneous distribution of dental caries, with pockets of severe caries, emphasizes the need for regular dental visits and school oral health programmes that could prevent the onset and subsequent progression of dental caries.

More than half of the sample (55\%) was either overweight or obese, and many of them could grow into obese adults and possibly suffer from metabolic diseases (17). The high prevalence of overweight and obesity is consistent with previous studies of adolescents in the Middle East (6). Possible reasons for this high prevalence include the increased consumption of fried foods, foods with a high fat content and a lack of physical activity (6). This calls for immediate actions to be taken by school administrations with regards to the type of food products being offered

\begin{tabular}{|c|c|c|c|c|c|c|}
\hline \multirow[t]{2}{*}{ BMI group comparisons } & \multicolumn{3}{|c|}{ Unadjusted (crude) OR } & \multicolumn{3}{|c|}{ Adjusted OR } \\
\hline & OR & $95 \% \mathrm{Cl}$ & $P$ value & OR & $95 \% \mathrm{Cl}$ & $P$ value \\
\hline $\begin{array}{l}\text { Underweight vs normal, } \\
\text { overweight \& obese }\end{array}$ & 1.30 & $0.88-1.93$ & 0.253 & - & - & - \\
\hline $\begin{array}{l}\text { Normal vs } \\
\text { overweight \& obese }\end{array}$ & 1.30 & $1.06-1.59$ & 0.012 & 1.77 & $1.11-2.82$ & 0.016 \\
\hline $\begin{array}{l}\text { Overweight vs } \\
\text { normal \& obese }\end{array}$ & 0.80 & $0.62-1.04$ & 0.085 & 0.94 & $0.56-1.59$ & 0.822 \\
\hline $\begin{array}{l}\text { Obese vs } \\
\text { normal \& overweight }\end{array}$ & 0.88 & $0.70-1.11$ & 0.281 & 0.75 & $0.47-1.05$ & 0.11 \\
\hline
\end{tabular}

For adjusted $O R$, adjustments were made for age, school, sport activities and dietary intake variables.

$P$ values in bold are statistically significant.

Normal weight refers to all individuals who were classified as having normal BMI according to World Health Organization criteria.

$B M I=$ body mass index; $C I=$ confidence interval; $O R=$ odds ratio. 


\begin{tabular}{|c|c|c|c|c|c|}
\hline \multirow{2}{*}{$\begin{array}{l}\text { Caries severity using } \\
\text { DMFT categories }\end{array}$} & \multirow[t]{2}{*}{$n(\%)$} & \multirow[t]{2}{*}{ Mean (SD) BMI, kg/m² } & \multicolumn{2}{|c|}{$95 \%$ confidence interval } & \multirow[t]{2}{*}{$P$ value } \\
\hline & & & Lower limit & Upper limit & \\
\hline 0 (caries free) & $207(51)$ & 22.69 (5.03) & 22.0 & 23.38 & \multirow{4}{*}{$0.006^{*}$} \\
\hline 1-3 (mild caries) & $137(34)$ & $22.18(5.50)$ & 21.26 & 23.11 & \\
\hline$\geq 4$ (severe caries) & $58(15)$ & $20.26(4.31)$ & 19.13 & 21.39 & \\
\hline Total & $402(100)$ & $22.17(5.15)$ & 21.66 & 22.67 & \\
\hline
\end{tabular}

*Statistically significant at the 0.01 level using analysis of variance.

$B M I=$ body mass index; $D M F T=$ decayed, missing and filled teeth; $S D=$ standard deviation .

and, more importantly, by the parents at home.

There was a significant inverse association between the DMFT and BMI scores. Normal weight children had a significantly higher mean DMFT score and prevalence of caries compared to the overweight and obese participants. This significant inverse association remained significant even after controlling for possible confounders by means of linear regression. This result confirmed previous studies and highlights an unusual trend in the Middle East $(18,19)$. Sugar is one of the risk factors for the development of caries and obesity. Hence, it can be assumed that if the sugar consumption increases, dental caries and BMI should also increase. However, these studies have shown that as BMI increases, caries prevalence and

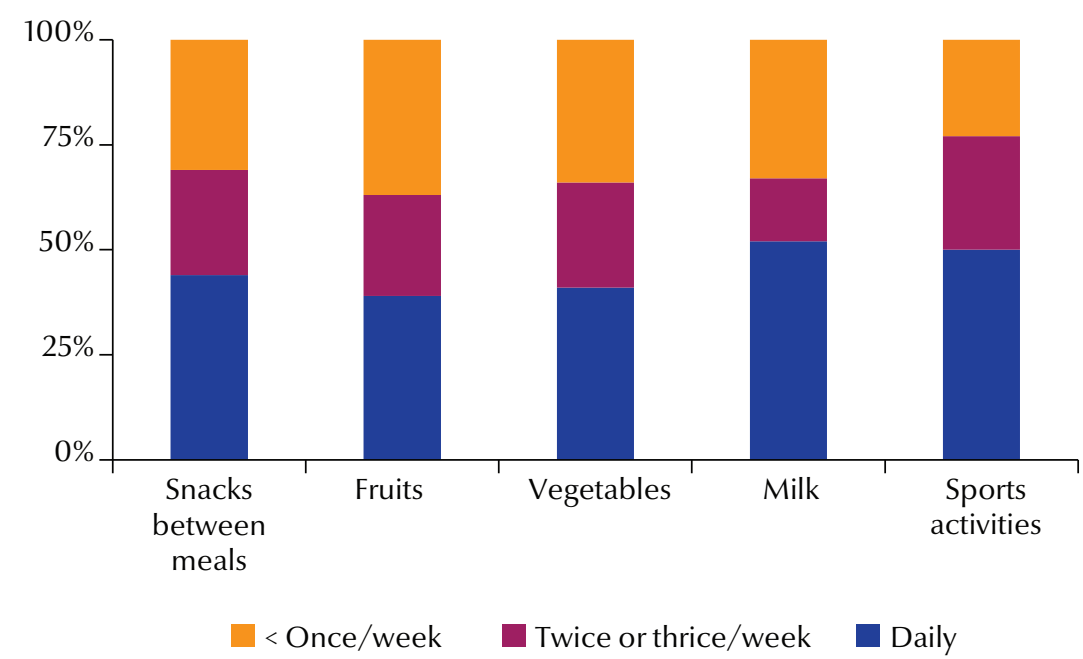

Figure 1 Percentage of the total sample $(n=402)$ with regards to frequency of sports activities and consumption of certain dietary products.

severity decrease $(18,19)$. The cause of this inverse relationship is not clearly understood, but it may be attributed to the unique dietary patterns found in this region. The common diet comprises fried foods that are loaded with fat but have low amounts of refined carbohydrates. This could increase the BMI and not necessarily have a direct effect on dental caries.

We used an additional statistical test to confirm the inverse relationship between caries and BMI. Previous studies have shown that if continuous data, like BMI, are categorized into groups, such as normal weight, overweight and obese, insignificant statistical associations could be interpreted as significant, which could result in insignificant associations being interpreted as significant ones (20). To prevent this, we used 
The protective effect of obesity on dental caries could also be explained by an increase in saliva production due to increased food consumption (22). This increase in saliva could act as a mechanical cleanser, buffering the low $\mathrm{pH}$ produced by bacteria, and hence reducing the incidence of dental caries.

Although some studies have reported that children with a high DMFT score were more likely to be overweight or obese, these studies compared the $\mathrm{BMI}$ categories and not the mean BMI with the DMFT score, which may have affected the results $(23,24)$. In addition, the dietary habits were different from those in the current study. In the previous studies, overweight and obese children consumed more sweetened junk foods compared to children in the normal weight range. This increased both the BMI and DMFT scores (24). Another reason for the contradictory results could be that some studies analysed the caries status of both the primary and permanent dentitions, while the current study was limited to the permanent dentition. The inclusion of both dentitions at different ages could have skewed the caries prevalence and affected the association between caries and BMI.

There were no significant associations between dietary habits and DMFT scores. This could be due to response acquiescence. The students may have answered the questionnaire based on their knowledge rather than on their actual eating habits. Saudi Arabia has launched many educational campaigns focusing on healthy lifestyle to try and reduce the prevalence of overweight and obesity among school children. This could have improved the students' knowledge on healthy versus unhealthy foods and their effects on health. Therefore, this may have influenced their responses and contributed to the weak correlations between caries and the supposed diet that they were consuming. This was confirmed by the poor responses obtained regarding the diet consumed at schools. Many respondents reported eating junk food regularly while few admitted that they consumed fruit and milk. This has severe implications for oral health, systemic health and intellectual development $(10,25)$. School management should regulate the types of foods being sold in the cafeteria and the types of lunch and snacks being brought from home. This could ensure that children are directed towards eating a healthier diet.

\section{Limitations}

The sample comprised only boys because of accessibility limitations. Further studies are required to determine whether these results are common to both genders. Moreover, this study was conducted on a convenience sample, inferring that the results should be interpreted with caution. The dietary questionnaire did not include the volume of food consumed, specific types of food and beverages consumed, oral hygiene practices and socioeconomic status. Future studies should include these variables. It must be noted that students could have answered based on their knowledge and not on their actual dietary intake, which could have skewed the results. Lastly, caries was scored using the DMFT index. This index classifies only frank caries as decayed; early caries and white spot lesions are classified as healthy. This often results in an underestimation of the true disease burden. Future studies should use a more sensitive index that can detect early caries.

\section{Conclusion}

Within the limits of the study, we observed a significant inverse relationship between dental caries and BMI among grade 6 students in Medina. Those in the underweight and normal BMI groups had the highest prevalence of caries and were almost 2 times greater at risk of developing caries compared to the overweight and obese groups. Although the prevalence of caries was low, the decayed component contributed most to the DMFT index, which emphasized the unmet dental burden of these participants. In general, they had poor dietary habits and there were no significant associations between any of the dietary variables and caries. We recommend: (1) regulation of the type of food being sold and brought into school; (2) implementation of oral hygiene education in schools; and (3) stressing the importance of regular dental check-ups, which would identify, treat and subsequently reduce oral health disorders such as dental caries.

\section{Acknowledgements}

The authors would like to thank Dr Ahmed Marghalani and Dr Mohammed Sarhan from the Department of Preventive Dental Sciences at Taibah University for their invaluable assistance in helping collect the data. In addition, special thanks must be given to the 2014 final year dental students of the Taibah University Dental College \& Hospital for assisting with the data collection and entry.

Funding: Funding was obtained from the Deanship of Scientific Research, Taibah University. The research grant number is 6121/1435.

Competing interests: None declared.

\section{References}

1. Te Morenga L, Mallard S, Mann J. Dietary sugars and body weight: systematic review and meta-analysis of randomised controlled trials and cohort studies. BMJ. 2013;346:e7492 (http://dx.doi.org/10.1136/bmj.e7492).
2. Hayden C, Bowler JO, Chambers S, Freeman R, Humphris G, Richards D, et al. Obesity and dental caries in children: a systematic review and meta-analysis. Community Dent Oral Epidemiol. 2013 Aug;41(4):289-308. PMID:23157709 
3. Mohammadi TM, Hossienian Z. The association between body mass index with dental caries in an Iranian sample. J Oral Health Oral Epidemiol. 2012;1(1):29-35 (http://johoe.kmu. ac.ir/index.php/johoe/article/view/9).

4. Parkar SM, Chokshi M. Exploring the association between dental caries and body mass index in public school children of Ahmadabad city, Gujarat. SRM J Res Dent Sci. 2013;4:101-5.

5. Mirmiran P, Sherafat-Kazemzadeh R, Jalali-Farahani S, Azizi F. Childhood obesity in the Middle East: a review. East Mediterr Health J. 2010 Sep;16(9):1009-17. PMID:21218730

6. Al-Rethaiaa AS, Fahmy AE, Al-Shwaiyat NM. Obesity and eating habits among college students in Saudi Arabia: a cross sectional study. Nutr J. 2010 09 19;9:39-45. PMID:20849655

7. Al-Qahtani A, Al-Ghamdi RA, Al-Ghamdi KS. Childhood obesity: Prevalence, risk factors and lifestyle behavior among primary school male children in Al-Madinah Al- Munawarah, Saudi Arabia. Int J Med Sci Public Health. 2013;2(4):1085-89 (http://www.scopemed.org/fulltextpdf.php?mno=43964).

8. Al Shehri A, Al Fattani A, Al Alwan I. Obesity among Saudi children. Saudi J Obes. 2013;1:3-9.

9. Oral health survey: basic methods. Geneva: World Health Organization; 1997.

10. Al-Muammar MN, El-Shafie M, Feroze S. Association between dietary habits and body mass index of adolescent females in intermediate schools in Riyadh, Saudi Arabia. East Mediterr Health J. 2014 Feb 11;20(1):39-45. PMID:24932932

11. Yahia N, Achkar A, Abdallah A, Rizk S. Eating habits and obesity among Lebanese university students. Nutr J. 2008 Oct 30;7:32. PMID:18973661

12. de Onis M, Onyango AW, Borghi E, Siyam A, Nishida C, Siekmann J. Development of a WHO growth reference for schoolaged children and adolescents. Bull World Health Organ. 2007 Sep;85(9):660-7. PMID:18026621

13. Bhayat A, Ahmad MS, Hifnawy T, Mahrous MS, Al-Shorman $\mathrm{H}$, Abu-Naba'a L, et al. Correlating dental caries with oral bacteria and the buffering capacity of saliva in children in Madinah, Saudi Arabia. J Int Soc Prev Community Dent. 2013 Jan;3(1):38-43. PMID:24478979

14. Bhayat A, Ahmad MS. Oral health status of 12-year-old male schoolchildren in Medina, Saudi Arabia. East Mediterr Health J. 201412 17;20(11):732-7. PMID:25601812
15. Al-Hussyeen AJ. Factors affecting utilization of dental health services and satisfaction among adolescent females in Riyadh City. Saudi Dent J. 2010 Jan;22(1):19-25. PMID:23960475

16. Al Agili DE, Alaki SM. Can Socioeconomic status indicators predict caries risk in schoolchildren in Saudi Arabia? a crosssectional study. Oral Health Prev Dent. 2014;12(3):277-88. PMID:24624395

17. Ekelund U, Ong KK, Linné Y, Neovius M, Brage S, Dunger DB, et al. Association of weight gain in infancy and early childhood with metabolic risk in young adults. J Clin Endocrinol Metab. 2007 Jan;92(1):98-103. PMID:17032722

18. Alkarimi HA, Watt RG, Pikhart H, Sheiham A, Tsakos G. Dental caries and growth in school-age children. Pediatrics. 2014 Mar;133(3):e616-23. PMID:24534405

19. Goodson JM, Tavares M, Wang X, et al. Obesity and dental decay: inference on the role of dietary sugar. PLoS One. 2013 Oct 10; 8(10):e74461. PMID:24130667

20. Owen SV, Froman RD. Why carve up your continuous data? Res Nurs Health. 2005 Dec;28(6):496-503. PMID:16287057

21. Tang RS, Huang MC, Huang ST. Relationship between dental caries status and anemia in children with severe early childhood caries. Kaohsiung J Med Sci. 2013 Jun;29(6):330-6. PMID:23684139

22. Lenander-Lumikari M, Loimaranta V. Saliva and dental caries. Adv Dent Res. 2000 Dec;14:40-7. PMID:11842922

23. Sharma A, Hegde AM. Relationship between body mass index, caries experience and dietary preferences in children. J Clin Pediatr Dent. 2009 Fall;34(1):49-52. PMID:19953809

24. Alm A, Isaksson H, Fåhraeus C, Koch G, Andersson-Gäre B, Nilsson $\mathrm{M}$, et al. BMI status in Swedish children and young adults in relation to caries prevalence. Swed Dent J. 2011;35(1):1-8. PMID:21591594

25. Kumar S, Kroon J, Lalloo R. A systematic review of the impact of parental socio-economic status and home environment characteristics on children's oral health related quality of life. Health Qual Life Outcomes. 2014 Mar 21;12:41. PMID:24650192 